\title{
Two solutions to Kirchhoff-type fourth-order implusive elastic beam equations
}

Jian Liu ${ }^{1 *}$ and Wenguang $\mathrm{Yu}^{2}$

\section{"Correspondence:}

sxkj163@163.com

'School of Mathematics and

Quantitative Economics, Shandong

University of Finance and

Economics, Jinan, 250014, China

Full list of author information is

available at the end of the article

\begin{abstract}
In this paper, the existence of two solutions for superlinear fourth-order impulsive elastic beam equations is obtained. We get two theorems via variational methods and corresponding two-critical-point theorems. Combining with the Newton-iterative method, an example is presented to illustrate the value of the obtained theorems.
\end{abstract}

MSC: $34 \mathrm{~B} 15 ; 58 \mathrm{E} 30$

Keywords: Two solutions; Elastic beam equations; Variational method; Impulsive effects

\section{Introduction}

In recent ten years, research on the existence numbers of solutions to nonlinear differential equations has been widely performed via corresponding critical point theorems, for example, $[2,6,9-11,14-17]$ and the references therein, and the aim of this paper is to obtain the existence of two solutions to Kirchhoff-type fourth-order impulsive elastic beam equations.

In [5], Bonanno et al. considered the existence of two positive solutions for superlinear Neumann problems with a complete Sturm-Liouville operator:

$$
\left\{\begin{array}{l}
-\left(p(x) u^{\prime}\right)^{\prime}+r(x) u^{\prime}(t)+q(x) u(t)=\lambda f(x, u), \quad x \in[a, b] \\
u^{\prime}(a)=u^{\prime}(b)=0
\end{array}\right.
$$

under the Amberosetti-Rabinowitz condition combining with a local condition not adding on zero point.

In [8], D'Aguì et al. studied the existence results of two non-zero solutions for some Sturm-Liouville equations involving the $p$-Laplacian operators with Robin boundary conditions:

$$
\left\{\begin{array}{l}
-\left(q(x)\left|u^{\prime}(x)\right|^{p-2} u^{\prime}(t)\right)^{\prime}+s(x)|u(x)|^{p-2} u(x)=\lambda f(t, u), \quad x \in[a, b] \\
u(a)=u^{\prime}(b)=0 .
\end{array}\right.
$$

(c) The Author(s) 2021. This article is licensed under a Creative Commons Attribution 4.0 International License, which permits use, sharing, adaptation, distribution and reproduction in any medium or format, as long as you give appropriate credit to the original author(s) and the source, provide a link to the Creative Commons licence, and indicate if changes were made. The images or other third party material in this article are included in the article's Creative Commons licence, unless indicated otherwise in a credit line to the material. If material is not included in the article's Creative Commons licence and your intended use is not permitted by statutory regulation or exceeds the permitted use, you will need to obtain permission directly from the copyright holder. To view a copy of this licence, visit http://creativecommons.org/licenses/by/4.0/. 
In [13], we obtained the existence of triple solutions of the following second-order Hamiltonian systems with impulsive effects:

$$
\left\{\begin{array}{l}
\ddot{u}(t)+g(t) \dot{u}(t)-A(t) u(t)=-\lambda b(t) \nabla H(u) \quad \text { a.e. } t \in[0, T] \\
\triangle \dot{u}^{i}\left(t_{j}\right)=I_{i j}\left(u^{i}\left(t_{j}\right)\right), \quad i=1,2, \ldots, N ; j=1,2, \ldots, l, \\
u(0)-u(T)=\dot{u}(0)-\dot{u}(T)=0
\end{array}\right.
$$

via variational methods and three-critical-point theorems without adding superlinear or sublinear assumptions to the nonlinearity at zero nor infinity.

In [12], we obtained the existence of at least three solutions to the impulsive equations with small non-autonomous perturbations

$$
\left\{\begin{array}{l}
-u^{\prime \prime}(t)+u(t)+p(t) u^{\prime}(t)=\lambda f(t, u)+\mu g(t, u) \quad \text { a.e. } t \in[0, T] \\
\Delta u^{\prime}\left(t_{i}\right)=I_{i}\left(u\left(t_{i}\right)\right), \quad i=1,2, \ldots, p \\
u(0)=u(T)=0
\end{array}\right.
$$

when the nonlinearity satisfies some superlinear conditions.

In [7], D'Aguì et al. considered the fourth-order differential equations with impulsive effects

$$
\left\{\begin{array}{l}
u^{(4)}+A u^{\prime \prime}+B u=\lambda f(x, u) \quad \text { in }[0,1] \\
u(0)=u(1)=0 \\
u^{\prime \prime}(0)=u^{\prime \prime}(1)=0
\end{array}\right.
$$

where $A, B$ are real constants, $f:[0,1] \times \mathbb{R} \rightarrow \mathbb{R}$ is a $L^{1}$-Carathéodory function. They gave some criteria to guarantee the differential equations have at least two non-trivial solutions.

Motivated by the above-mentioned work, in this article, we consider the following Kirchhoff-type fourth-order differential equations with impulsive effects:

$$
\left\{\begin{array}{l}
u^{(i v)}+K\left(\int_{0}^{1}\left(-\alpha\left|u^{\prime}(t)\right|^{2}+\beta|u(t)|^{2}\right) d t\right)\left(\alpha u^{\prime \prime}+\beta u\right)=\lambda f(t, u) \quad \text { a.e. } t \in[0,1] \\
\Delta u^{\prime \prime}\left(t_{i}\right)=I_{1 i}\left(u^{\prime}\left(t_{i}\right)\right), \quad i=1,2, \ldots, l, \\
-\Delta u^{\prime \prime \prime}\left(t_{i}\right)=I_{2 i}\left(u\left(t_{i}\right)\right), \quad i=1,2, \ldots, l, \\
u(0)=u(1)=0, \\
u^{\prime \prime}(0)=u^{\prime \prime}(1)=0,
\end{array}\right.
$$

where $K:[0,+\infty) \rightarrow \mathbb{R}$ is a continuous function such that there exist two constants $m_{0}$ and $m_{1}$ satisfying $0<m_{0} \leq K(x) \leq m_{1}, \forall x \geq 0, \alpha \leq 0, \beta \geq 0$ are real constants, $\lambda$ is a positive real parameter, $f:[0,1] \times \mathbb{R} \rightarrow \mathbb{R}$ is a $L^{1}$-Carathéodory function, $0=t_{0}<t_{1}<\cdots<t_{l}<$ $t_{l+1}=1, \Delta u^{\prime \prime}\left(t_{i}\right)=u^{\prime \prime}\left(t_{i}^{+}\right)-u^{\prime \prime}\left(t_{i}^{-}\right), \Delta u^{\prime \prime \prime}\left(t_{i}\right)=u^{\prime \prime \prime}\left(t_{i}^{+}\right)-u^{\prime \prime \prime}\left(t_{i}^{-}\right)$, and $I_{j i}(j=1,2 ; i=1,2, \ldots, l) \in$ $C(\mathbb{R}, \mathbb{R})$. We aim to get the existence of at least two solutions. We find the existence of at least two solutions without assuming any asymptotic conditions neither at zero or at infinity on nonlinear items. Our main tools are variational methods and two-critical-point theorems by Bonanno and Marano. 


\section{Preliminaries}

We consider the spaces

$$
\begin{aligned}
& H_{0}^{1}(0,1):=\left\{u \in L^{2}([0,1]): u^{\prime} \in L^{2}([0,1]), u(0)=u(1)=0\right\}, \\
& H^{2}(0,1):=\left\{u \in L^{2}([0,1]): u^{\prime}, u^{\prime \prime} \in L^{2}([0,1])\right\} .
\end{aligned}
$$

Take $X=H_{0}^{1}(0,1) \cap H^{2}(0,1)$, thus $X$ is a Hilbert space with the inner product

$$
\langle u, v\rangle:=\int_{0}^{1} u^{\prime \prime}(t) v^{\prime \prime}(t) d t
$$

and the induced norm

$$
\|u\|:=\left(\int_{0}^{1}\left(u^{\prime \prime}(t)\right)^{2} d t\right)^{1 / 2}
$$

By direct calculation one finds that the norm $\|u\|$ is equivalent to the following norm:

$$
\|u\|_{X}=\left(\int_{0}^{1}\left(\left|u^{\prime \prime}(t)\right|^{2}-\alpha\left|u^{\prime}(t)\right|^{2}+\beta|u(t)|^{2}\right) d t\right)^{1 / 2}
$$

for more details, see [4].

It is well known that the embedding $X \hookrightarrow C^{1}([0,1])$ is compact and there exists a positive constant $k=1+\frac{1}{\pi}$ such that

$$
\|u\|_{\infty}:=\max \left\{\max _{t \in[0,1]}|u(t)|, \max _{t \in[0,1]}\left|u^{\prime}(t)\right|\right\} \leq k\|u\|_{X}
$$

for all $u \in X$ (see [18]).

We call that $u \in X$ is a weak solution of problem (1.6) if

$$
\begin{aligned}
& \int_{0}^{1}\left(u^{\prime \prime}(t) v^{\prime \prime}(t) d t+K\left(\int_{0}^{1}\left(-\alpha\left|u^{\prime}(t)\right|^{2}+\beta|u(t)|^{2}\right) d t\right) \int_{0}^{1}\left(-\alpha u^{\prime}(t) v^{\prime}(t)+\beta u(t) v(t)\right) d t\right. \\
& +\sum_{i=1}^{l} I_{1 i}\left(u^{\prime}\left(t_{i}\right)\right) v^{\prime}\left(t_{i}\right)+\sum_{i=1}^{l} I_{2 i}\left(u\left(t_{i}\right)\right) v\left(t_{i}\right)-\lambda \int_{0}^{1} f(t, u(t)) v(t) d t=0
\end{aligned}
$$

holds for any $v \in X$.

Put

$$
F(t, u)=\int_{0}^{u} f(t, \xi) d \xi \quad \text { for all }(t, u) \in[0,1] \times \mathbb{R} .
$$

Let the functional $I_{\lambda}: X \rightarrow \mathbb{R}$ be defined by

$$
I_{\lambda}(u)=\Phi(u)-\lambda \Psi(u)
$$


where

$$
\begin{aligned}
\Phi(u)= & \frac{1}{2}\|u\|^{2}+\frac{1}{2} \int_{0}^{\int_{0}^{1}\left(-\alpha\left|u^{\prime}(t)\right|^{2}+\beta|u(t)|^{2}\right) d t} K(s) d s+\sum_{i=1}^{l} \int_{0}^{u^{\prime}\left(t_{i}\right)} I_{1 i}(t) d t \\
& +\sum_{i=1}^{l} \int_{0}^{u\left(t_{i}\right)} I_{2 i}(t) d t, \\
\Psi(u)= & \int_{0}^{1} F(t, u) d t .
\end{aligned}
$$

Lemma 2.1 $\Phi, \Psi$ are well defined and Gâteaux differentiable at any $u \in X$ and

$$
\begin{aligned}
\left\langle\Phi^{\prime}(u), v\right\rangle= & \int_{0}^{1}\left(u^{\prime \prime}(t) v^{\prime \prime}(t) d t+K\left(\int_{0}^{1}\left(-\alpha\left|u^{\prime}(t)\right|^{2}+\beta|u(t)|^{2}\right) d t\right)\right. \\
& \times \int_{0}^{1}\left(-\alpha u^{\prime}(t) v^{\prime}(t)+\beta u(t) v(t)\right) d t \\
& +\sum_{i=1}^{l} I_{1 i}\left(u^{\prime}\left(t_{i}\right)\right) v^{\prime}\left(t_{i}\right)+\sum_{i=1}^{l} I_{2 i}\left(u\left(t_{i}\right)\right) v\left(t_{i}\right), \\
\left\langle\Psi^{\prime}(u), v\right\rangle= & \int_{0}^{1} f(t, u(t)) v(t) d t, \quad \forall v \in X .
\end{aligned}
$$

Lemma 2.2 If $u \in X$ satisfying $I_{\lambda}^{\prime}(u)=0$, then $u$ is a weak solution of the Kirchhoff-type system (1.6).

Theorem 2.3 ([1], Theorem 3.2) Let $X$ be a real Banach space and let $\Phi, \Psi: X \rightarrow R$ be two continuous Gâteaux differentiable functions such that $\Phi$ is bounded from below and $\Phi(0)-\Psi(0)=0$. Fix $r>0$ such that $\sup _{\Phi(u)<r} \Psi(u)<+\infty$ and assume that for each

$$
\lambda \in\left(0, \frac{r}{\sup _{\Phi(u) \leq r} \Psi(u)}\right)
$$

the functional $\Phi-\lambda \Psi$ satisfies the (P.S.)-condition and it is unbounded from below. Then, for each $\lambda \in\left(0, \frac{r}{\sup _{\Phi(u) \leq r} \Psi(u)}\right)$, the functional $\Phi-\lambda \Psi$ admits at least two distinct critical points.

Theorem 2.4 ([3], Theorem 2.1) Let $X$ be a real Banach space and let $\Phi, \Psi: X \rightarrow R$ be two continuous Gâteaux differentiable functions such that $\inf _{X} \Phi=\Phi(0)-\Psi(0)=0$. Assume there are $r \in \mathbb{R}$ and $\bar{u} \in X$, with $0<\Phi(\bar{u})<r$ such that

$$
\frac{\sup _{\Phi(u) \leq r} \Psi(u)}{r}<\frac{\Psi(\bar{u})}{\Phi(\bar{u})}
$$

and, for each $\lambda \in\left(\frac{\Phi(\bar{u})}{\Psi(\bar{u})}, \frac{r}{\sup _{\Phi(u) \leq r} \Psi(u)}\right)$, the functional $I_{\lambda}=\Phi-\lambda \Psi$ satisfies the (P.S.)-condition and it is unbounded from below. Then, for each $\lambda \in\left(\frac{\Phi(\bar{u})}{\Psi(\bar{u})}, \frac{r}{\sup _{\Phi(x)<r} \Psi(u)}\right)$, the functional $I_{\lambda}$ admits at least two non-zero critical points $u_{\lambda, 1}, u_{\lambda, 2}$ such that $I_{\lambda}\left(u_{\lambda, 1}\right)<0<I_{\lambda}\left(u_{\lambda, 2}\right)$.

Definition 2.5 ([7], Definition 2.1) $f:[0,1] \times \mathbb{R} \rightarrow \mathbb{R}$ is an $L^{1}$-Carathéodory function if: 
(1) $x \mapsto f(x, \xi)$ is measurable for every $\xi \in \mathbb{R}$;

(2) $\xi \mapsto f(x, \xi)$ is continuous for almost every $x \in[0,1]$;

(3) for every $s>0$ there is a function $l_{s} \in L^{1}([0,1])$ such that

$$
\sup _{|\xi| \leq s}|f(x, \xi)| \leq l_{s}(x)
$$

for a.e. $x \in[0,1]$.

\section{Main results}

Our main results are the following two theorems about the existence of at least two distinct solutions to the Kirchhoff-type system (1.6).

Theorem 3.1 Assume the following assumptions:

(H1) there exists $\mu>\frac{2 m_{1}}{m_{0}}$ such that

$$
0<\mu F(t, u) \leq f(t, u) u, \quad \forall t \in[0,1], u \in \mathbb{R} \backslash\{0\}
$$

(H2) there exist positive constants $L_{i}(i=1,2, \ldots, l)$ such that

$$
\left|I_{1 i}(u)-I_{1 i}(v)\right| \leq L_{i}|u-v|, \quad \forall u, v \in \mathbb{R}
$$

(H3) $0<I_{1 i}(u) u \leq \mu \int_{0}^{u^{\prime}} I_{1 i}(t) d t, 0<I_{2 i}(u) u \leq \mu \int_{0}^{u} I_{2 i}(t) d t \leq \mu \delta|u|^{2}, i=1,2, \ldots, l, \forall u \in$ $\mathbb{R} \backslash\{0\}$, then there exists $c>0$ such that, when

$$
\lambda \in\left(0, \frac{c^{2}}{2 k^{2} \int_{0}^{1} \max _{|u| \leq c} F(t, u) d t}\right),
$$

the functional $I_{\lambda}$ admits at least two distinct critical points.

Proof In view of condition (H3) and $0<m_{0} \leq K(x) \leq m_{1}, \forall x \geq 0$, there exists a constant $c_{1}>0$, such that

$$
\begin{aligned}
\Phi(u)= & \frac{1}{2}\|u\|^{2}+\frac{1}{2} \int_{0}^{\int_{0}^{1}\left(-\alpha\left|u^{\prime}(t)\right|^{2}+\beta|u(t)|^{2}\right) d t} K(s) d s+\sum_{i=1}^{l} \int_{0}^{u^{\prime}\left(t_{i}\right)} I_{1 i}(t) d t \\
& +\sum_{i=1}^{l} \int_{0}^{u\left(t_{i}\right)} I_{2 i}(t) d t \geq c_{1}\|u\|_{X}^{2}
\end{aligned}
$$

thus one finds that $\Phi$ is bounded from below.

Let $\left\{u_{n}\right\} \in X$ such that $\left\{I_{\lambda}\left(u_{n}\right)\right\}$ is bounded and $I_{\lambda}^{\prime}\left(u_{n}\right) \rightarrow 0$, as $n \rightarrow+\infty$, then we prove that $\left\{u_{n}\right\}$ is bounded in $X$. In fact, combining (H1), (H3), (2.2) with (2.3), one has

$$
\begin{aligned}
\mu I_{\lambda}\left(u_{n}\right)-I_{\lambda}^{\prime}\left(u_{n}\right) u_{n} & \\
= & \left(\frac{\mu}{2}-1\right)\left\|u_{n}\right\|^{2} \\
& +\frac{\mu}{2} \int_{0}^{\int_{0}^{1}\left(-\alpha\left|u_{n}^{\prime}(t)\right|^{2}+\beta\left|u_{n}(t)\right|^{2}\right) d t} K(s) d s
\end{aligned}
$$




$$
\begin{aligned}
& -K\left(\int_{0}^{1}\left(-\alpha\left|u_{n}^{\prime}(t)\right|^{2}+\beta\left|u_{n}(t)\right|^{2}\right) d t\right) \int_{0}^{1}\left(-\alpha u_{n}^{\prime}(t)^{2}+\beta u_{n}(t)^{2}\right) d t \\
& +\mu \sum_{i=1}^{l} \int_{0}^{u_{n}^{\prime}\left(t_{i}\right)} I_{1 i}(t) d t-\sum_{i=1}^{l} I_{1 i}\left(u_{n}^{\prime}\left(t_{i}\right)\right) u_{n}^{\prime}\left(t_{i}\right)+\sum_{i=1}^{l} \int_{0}^{u_{n}\left(t_{i}\right)} I_{2 i}(t) d t \\
& \left.-\sum_{i=1}^{l} I_{2 i}\left(u_{n}\left(t_{i}\right)\right) u_{n}\left(t_{i}\right)-\lambda \mu \int_{0}^{1} F\left(t, u_{n}\right)\right) d t+\lambda \int_{0}^{1} f\left(t, u_{n}\right) u_{n} d t \\
\geq & \left(\frac{\mu}{2}-1\right)\left\|u_{n}\right\|^{2}+\left(\frac{\mu}{2} m_{0}-m_{1}\right) \int_{0}^{1}\left(-\alpha\left|u_{n}^{\prime}(t)\right|^{2}+\beta\left|u_{n}(t)\right|^{2}\right) d t \\
\geq & \min \left\{\frac{\mu}{2}-1, \frac{\mu}{2} m_{0}-m_{1}\right\}\left\|u_{n}\right\|_{X}^{2},
\end{aligned}
$$

which implies that $\left\{u_{n}\right\}$ is bounded in view of $\mu>\frac{2 m_{1}}{m_{0}}$.

Hence there exists a subsequence $\left\{u_{n_{k}}\right\}$ of $\left\{u_{n}\right\}$ converging uniformly to $u$ in $[0,1]$. Thus, when $k \rightarrow+\infty$, one has

$$
\begin{aligned}
& \left(I_{\lambda}^{\prime}\left(u_{n_{k}}\right)-I_{\lambda}^{\prime}(u)\right)\left(u_{n_{k}}-u\right) \rightarrow 0 \\
& \int_{0}^{1}\left(f\left(t, u_{n_{k}}\right)-f(t, u)\right)\left(u_{n_{k}}-u\right) d t \rightarrow 0, \\
& \left(I_{2 i}\left(u_{n_{k}}\left(t_{i}\right)\right)-I_{2 i}\left(u\left(t_{i}\right)\right)\right)\left(u_{n_{k}}\left(t_{i}\right)-u\left(t_{i}\right)\right) \rightarrow 0, \quad i=1,2, \ldots, l .
\end{aligned}
$$

Thus, by standard direct calculations, one finds that there exists a positive constant $c_{2}$ satisfying $a<c_{2}<b$, where

$$
\begin{aligned}
& a=\min \left\{1, K\left(\int_{0}^{1}\left(-\alpha\left|u_{n k}^{\prime}(t)\right|^{2}+\beta\left|u_{n k}(t)\right|^{2}\right) d t\right), K\left(\int_{0}^{1}\left(-\alpha\left|u^{\prime}(t)\right|^{2}+\beta|u(t)|^{2}\right) d t\right)\right\} \\
& b=\max \left\{1, K\left(\int_{0}^{1}\left(-\alpha\left|u_{n k}^{\prime}(t)\right|^{2}+\beta\left|u_{n k}(t)\right|^{2}\right) d t\right), K\left(\int_{0}^{1}\left(-\alpha\left|u^{\prime}(t)\right|^{2}+\beta|u(t)|^{2}\right) d t\right)\right\}
\end{aligned}
$$

such that

$$
\begin{aligned}
& \left(I_{\lambda}^{\prime}\left(u_{n_{k}}\right)-I_{\lambda}^{\prime}(u)\right)\left(u_{n_{k}}-u\right) \\
& =I_{\lambda}^{\prime}\left(u_{n_{k}}\right)\left(u_{n_{k}}-u\right)-I_{\lambda}^{\prime}(u)\left(u_{n_{k}}-u\right) \\
& =c_{2}\left\|u_{n_{k}}-u\right\|_{X}^{2} \\
& \quad+\sum_{i=1}^{l}\left(I_{1 i}\left(u_{n_{k}}^{\prime}\left(t_{i}\right)\right)-I_{1 i}\left(u^{\prime}\left(t_{i}\right)\right)\right)\left(u_{n_{k}}^{\prime}\left(t_{i}\right)-u^{\prime}\left(t_{i}\right)\right) \\
& \quad+\sum_{i=1}^{l}\left(I_{2 i}\left(u_{n_{k}}\left(t_{i}\right)\right)-I_{2 i}\left(u\left(t_{i}\right)\right)\right)\left(u_{n_{k}}\left(t_{i}\right)-u\left(t_{i}\right)\right) \\
& \quad-\int_{0}^{1}\left(f\left(t, u_{n_{k}}\right)-f(t, u)\right)\left(u_{n_{k}}(t)-u(t)\right) d t
\end{aligned}
$$

and

$$
\left(c_{2}-k^{2} \sum_{i=1}^{l} L_{i}\right)\left\|u_{n_{k}}-u\right\|_{X}^{2}
$$




$$
\begin{aligned}
& c_{2}\left\|u_{n_{k}}-u\right\|_{X}^{2}-k^{2} \sum_{i=1}^{l} L_{i}\left\|u_{n_{k}}-u\right\|_{X}^{2} \\
\leq & c_{2}\left\|u_{n_{k}}-u\right\|_{X}^{2}-\sum_{i=1}^{l} L_{i}\left\|u_{n_{k}}-u\right\|_{\infty}^{2} \\
\leq & \left\|u_{n_{k}}-u\right\|_{X}^{2}-\sum_{i=1}^{l} L_{i}\left|u_{n_{k}}^{\prime}\left(t_{i}\right)-u^{\prime}\left(t_{i}\right)\right|^{2} \\
\leq & c_{2}\left\|u_{n_{k}}-u\right\|_{X}^{2}-\sum_{i=1}^{l}\left|I_{1 i}\left(u_{n_{k}}^{\prime}\right)\left(t_{i}\right)-I_{1 i}\left(u^{\prime}\left(t_{i}\right)\right)\right|\left|u_{n_{k}}^{\prime}\left(t_{i}\right)-u^{\prime}\left(t_{i}\right)\right| \\
\leq & c_{2}\left\|u_{n_{k}}-u\right\|_{X}^{2}-\mid \sum_{i=1}^{l}\left(I_{1 i}\left(u_{n_{k}}^{\prime}\right)\left(t_{i}\right)-I_{1 i}\left(u^{\prime}\left(t_{i}\right)\right)\right)\left(u_{n_{k}}^{\prime}\left(t_{i}\right)-u^{\prime}\left(t_{i}\right) \mid\right. \\
\leq & \mid c_{2}\left\|u_{n_{k}}-u\right\|_{X}^{2}+\sum_{i=1}^{l}\left(I_{1 i}\left(u_{n_{k}}^{\prime}\right)\left(t_{i}\right)-I_{1 i}\left(u^{\prime}\left(t_{i}\right)\right)\right)\left(u_{n_{k}}^{\prime}\left(t_{i}\right)-u^{\prime}\left(t_{i}\right) \mid\right. \\
= & \left.\mid I_{\lambda}^{\prime}\left(u_{n_{k}}\right)-I_{\lambda}^{\prime}(u)\right)\left(u_{n_{k}}-u\right)+\int_{0}^{1}\left(f\left(t, u_{n_{k}}\right)-f(t, u)\right)\left(u_{n_{k}}(t)-u(t)\right) d t \\
& +\sum_{i=1}^{l}\left(I_{2 i}\left(u_{n_{k}}\left(t_{i}\right)\right)-I_{2 i}\left(u\left(t_{i}\right)\right)\right)\left(u_{n_{k}}\left(t_{i}\right)-u\left(t_{i}\right)\right) \mid .
\end{aligned}
$$

Combining (3.1), (3.2) with (3.3), we get $\left\|u_{n_{k}}-u\right\|_{X} \rightarrow 0$, as $k \rightarrow+\infty$, thus $\left\{u_{n_{k}}\right\}$ converges strongly to $u$ in $X$, then the functional $I_{\lambda}$ satisfies the (P.S.)-condition.

Next, we prove $I_{\lambda}$ is unbounded from below.

Noticing that $0<\mu F(t, u) \leq f(t, u) u, \forall t \in[0,1], u \in \mathbb{R} \backslash\{0\}$, one finds that there exist $\bar{\alpha}, \bar{\beta}>0$ such that $F(t, u) \geq \bar{\alpha}|u|^{\mu}-\bar{\beta}, u \in \mathbb{R} \backslash\{0\}$. We choose $\rho_{n}(t)=\xi_{n} \in \mathbb{R}$ satisfying $\left|\xi_{n}\right| \rightarrow+\infty$, thus $\xi_{n} \in X$. In view of $(2.2)$ and $\int_{0}^{u} I_{2 i}(t) d t \leq \delta|u|^{2}, i=1,2, \ldots, l, \forall u \in \mathbb{R} \backslash\{0\}$, we get

$$
I_{\lambda}\left(\rho_{n}\right) \leq \frac{1}{2} \beta m_{1}\left|\xi_{n}\right|^{2}+l \delta\left|\xi_{n}\right|^{2}-\lambda \bar{\alpha}\left|\xi_{n}\right|^{\mu}+\lambda \bar{\beta}
$$

noticing that $\mu>2$, and it leads to $I_{\lambda}\left(\rho_{n}\right) \rightarrow-\infty\left(\left|\rho_{n}\right| \rightarrow+\infty\right)$, thus one finds that the functional $I_{\lambda}$ is unbounded from below.

Taking account of (2.1), (2.2) and (H3), for all $u \in X$ satisfying $\Phi(u) \leq r$, one has $\|u\| \leq$ $\sqrt{2 r}$ because of $\|u\|_{\infty} \leq k\|u\|_{H} \leq k \sqrt{2 r}=: c$. Therefore,

$$
\begin{aligned}
\sup _{\Phi(u) \leq r} \Psi(u) & =\sup _{\Phi(u) \leq r} \int_{0}^{1} F(t, u) d x \\
& \leq \sup _{\Phi(u) \leq r} \int_{0}^{1} F(t, u) d x \\
& \leq \int_{0}^{1} \max _{|u| \leq c} F(t, u) d x \\
& \leq \int_{0}^{1} \max _{|u| \leq c} F(t, u) d x \\
& <+\infty
\end{aligned}
$$


Hence, by Theorem 2.3, one finds that the functional $I_{\lambda}$ admits at least two distinct critical points for $\lambda \in\left(0, \frac{c^{2}}{2 k^{2} \int_{0}^{1} \max _{|u| \leq c} F(t, u) d x}\right)$.

Theorem 3.2 Assume the conditions of Theorem 3.1 are satisfied. In addition, suppose there exist $c>0$ and $\bar{\xi} \in \mathbb{R}$ with $|\bar{\xi}|<\frac{c}{k \sqrt{\beta m_{1}+2 \delta l}}$, such that

$$
\frac{2 k^{2} \int_{0}^{1} \max _{|u| \leq c} F(t, u) d t}{c^{2}}<\frac{\int_{0}^{1} F(t, \bar{\xi}) d t}{\left(\frac{1}{2} \beta m_{1}+\delta l\right)|\bar{\xi}|^{2}}
$$

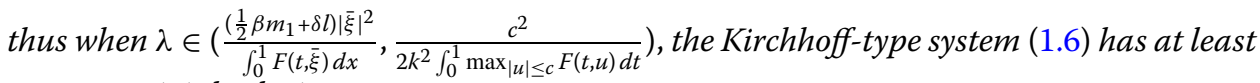
two non-trivial solutions.

Proof Choose $\bar{v}(t)=\bar{\xi}$, taking account of condition (H3), one has

$$
\begin{aligned}
\Phi(\bar{v}) & =\frac{1}{2}\|\bar{v}\|_{X}^{2}+\sum_{i=1}^{l} \int_{0}^{\bar{v}^{\prime}\left(t_{i}\right)} I_{1 i}(t) d t+\sum_{i=1}^{l} \int_{0}^{\bar{v}\left(t_{i}\right)} I_{2 i}(t) d t \\
& \geq \frac{1}{2} \beta m_{0}|\bar{\xi}|^{2}>0
\end{aligned}
$$

and

$$
\begin{aligned}
\Phi(\bar{v}) & =\frac{1}{2}\|\bar{v}\|_{X}^{2}+\sum_{i=1}^{l} \int_{0}^{\bar{v}^{\prime}\left(t_{i}\right)} I_{1 i}(t) d t+\sum_{i=1}^{l} \int_{0}^{\bar{v}\left(t_{i}\right)} I_{2 i}(t) d t \\
& \leq \frac{1}{2}|\bar{\xi}|^{2}+\delta \sum_{i=1}^{l}|\bar{\xi}|^{2} \\
& =\left(\frac{1}{2} \beta m_{1}+\delta l\right)|\bar{\xi}|^{2} \\
& <\frac{c^{2}}{2 k^{2}}=r .
\end{aligned}
$$

In view of (3.5) and (3.6), we get $0<\Phi(\bar{v})<r$.

Noting that $\Psi(\bar{v})=\int_{0}^{1} F(t, \bar{\xi}) d t$, by virtue of (3.4), we get

$$
\begin{aligned}
\frac{\sup _{\Phi(u) \leq r} \Psi(u)}{r} & \leq \frac{\int_{0}^{1} \max _{|u| \leq c} F(t, u) d x}{r} \\
& =\frac{2 k^{2} \int_{0}^{1} \max _{|u| \leq c} F(t, u) d x}{c^{2}} \\
& <\frac{\int_{0}^{1} F(t, \bar{\xi}) d t}{\left(\frac{1}{2} \beta m_{1}+\delta l\right)|\bar{\xi}|^{2}} \\
& <\frac{\Psi(\bar{v})}{\Phi(\bar{v})},
\end{aligned}
$$

so the conditions in Theorem 2.4 are all satisfied. Hence, we complete the proof.

Remark 3.3 Noting that $F(t, u)=\int_{0}^{u} f(t, \xi) d \xi$ for all $(t, u) \in[0,1] \times \mathbb{R}$ is continuous on $u \in$ $\mathbb{R}$, thus condition $(\mathrm{H} 1)$ can be replaced by the following condition: 
(H0) Suppose that there exist $\mu>2$ and $L>0$ such that

$$
0<\mu F(t, u) \leq f(t, u) u, \quad \forall t \in[0,1],|u| \geq L
$$

Example 3.4 Taking

$$
\begin{aligned}
& K(x)=\frac{3}{4}+\frac{1}{4} \sin x, \quad \forall x \in[0,+\infty), \\
& f(t, u)=\left\{\begin{array}{l}
\frac{1}{\sqrt{t(1-t)}}\left(6 u^{5}-404 u^{3}+200 u\right), \quad|u| \leq 10, \\
\frac{198,000}{\sqrt{t(1-t)}}\left(\frac{1}{750} u^{3}-\frac{1}{3}\right), \quad|u|>10,
\end{array}\right. \\
& F(t, u)= \begin{cases}\frac{1}{\sqrt{t(1-t)}}|u|^{2}\left(|u|^{2}-1\right)\left(|u|^{2}-100\right), \quad|u| \leq 10, \\
\frac{198,000}{\sqrt{t(1-t)}}\left(\frac{1}{3000} u^{4}-\frac{1}{3} u\right), & |u|>10,\end{cases} \\
& \quad l=1, \quad I_{1 i}(u)=\frac{1}{10} u, \quad I_{2 i}(u)= \begin{cases}u^{7}, & |u| \leq 1, \\
u^{\frac{1}{7}}, & |u|>1 .\end{cases}
\end{aligned}
$$

By calculation we know that $f(t, u)$ is a $L^{1}$-Carathéodory function in view of $\int_{0}^{1} \frac{1}{\sqrt{t(1-t)}} d t \doteq$ 3.142. Consider the Kirchhoff-type system (1.6), and we choose $c=10, \delta=\frac{7}{8}, \bar{\xi}=0.9$. There exists $0<|\bar{u}|<1$ such that $\max _{|u| \leq 10} F(t, u)=\max _{|u| \leq 1} F(t, u)=F(t, \bar{u})$, furthermore, by a Newton-iterative method we obtain $\bar{u}=0.706, F(1, \bar{u})=24.88$, by calculation, the Kirchhoff-type system (1.6) has at least two non-trivial solutions when $\lambda \in(0.029,0.369)$ by applying Theorem 3.2 and Remark 3.3.

\section{Conclusion}

The main novelty of our paper is that we apply a recent obtained critical-point theorem to the study of the superlinear fourth-order impulsive elastic beam equations, and the existence of at least two solutions of this kind of equations has been studied. The assumptions made and the related considerations are needed to set up the problem in a way that makes it suitable for the abstract framework, and we also improve many previous results.

Funding

This work is supported by National Natural Science Foundation of China (11571197) and the Taishan Scholars Program of Shandong Province (tsqn20161041).

\section{Availability of data and materials}

Not applicable.

Ethics approval and consent to participate

All authors contributed to each part of this study equally and declare that they have no competing interests.

Competing interests

The authors declare that they have no competing interests.

Authors' contributions

All authors contributed equally to the writing of this paper. The authors read and approved the final manuscript.

\section{Author details}

${ }^{1}$ School of Mathematics and Quantitative Economics, Shandong University of Finance and Economics, Jinan, 250014 ,

China. ${ }^{2}$ School of Insurance, Shandong University of Finance and Economics, Jinan, 250014, China. 


\section{Publisher's Note}

Springer Nature remains neutral with regard to jurisdictional claims in published maps and institutional affiliations.

Received: 2 December 2020 Accepted: 21 March 2021 Published online: 31 March 2021

\section{References}

1. Bonanno, G.: Relations between the mountain pass theorem and local minima. Adv. Nonlinear Anal. 1, 205-220 (2012)

2. Bonanno, G., Candito, P.: Non-differentiable functionals and applications to elliptic problems with discontinuous nonlinearities. J. Differ. Equ. 12, 3031-3059 (2008)

3. Bonanno, G., D'Aguì, G.: Two non-zero solutions for elliptic Dirichlet problems. Z. Anal. Anwend. 35, 449-464 (2016)

4. Bonanno, G., Di Bella, B.: A boundary value problem for fourth-order elastic beam equations. J. Math. Anal. Appl. 343, $1166-1176(2008)$

5. Bonanno, G., lannizzotto, A., Marras, M.: Two positive solutions for superlinear Neumann problems with a complete Sturm-Liouville operator. J. Convex Anal. 25, 421-434 (2018)

6. Bonanno, G., Livrea, R.: Multiple periodic solutions for Hamiltonian systems with not coercive potential. J. Math. Anal. Appl. 363, 627-638 (2010)

7. D'Aguì, G., Bella, B., Winkert, P.: Two positive solutions for nonlinear fourth-order elastic beam equations. Electron. J. Qual. Theory Differ. Equ. 2019, 37 (2019)

8. D'Aguì, G., Sciammetta, A., Tornatore, E.: Two non-zero solutions for Sturm-Liouville equations with mixed boundary conditions. Nonlinear Anal. 47, 324-331 (2019)

9. Liu, J., Yu, W.: Two solutions to superlinear Hamiltonian systems with impulsive effects. Appl. Math. Lett. 102, 106162 (2020)

10. Liu, J., Zhao, Z.: An application of variational methods to second-order impulsive differential equation with derivative dependence. Electron. J. Differ. Equ. 2014, 62 (2014)

11. Liu, J., Zhao, Z:: Variational approach to second-order damped Hamiltonian systems with impulsive effects. J. Nonlinear Sci. Appl. 9, 3459-3472 (2016)

12. Liu, J., Zhao, Z.: Multiple solutions for impulsive problems with non-autonomous perturbations. Appl. Math. Lett. 64 , 143-149 (2017)

13. Liu, J., Zhao, Z., Zhang, T.: Multiple solutions to damped Hamiltonian systems with impulsive effects. Appl. Math. Lett. 91, 173-180 (2019)

14. Nieto, J.: Variational formulation of a damped Dirichlet impulsive problem. Appl. Math. Lett. 23, 940-942 (2010)

15. Nieto, J., O'Regan, D.: Variational approach to impulsive differential equations. Nonlinear Anal. 10, 680-690 (2009)

16. Sun, J., Chen, H., Nieto, J., Otero-Novoa, M.: Multiplicity of solutions for perturbed second-order Hamiltonian systems with impulsive effects. Nonlinear Anal. 72, 4575-4586 (2010)

17. Sun, J., Chen, H., Yang, L.: Variational methods to fourth-order impulsive differential equations. J. Appl. Math. Comput. $35,323-340(2011)$

18. Xie, J., Luo, Z: Solutions to a boundary value problem of a fourth-order impulsive differential equation. Bound. Value Probl. 154, 1-18 (2013)

\section{Submit your manuscript to a SpringerOpen ${ }^{\circ}$ journal and benefit from:}

- Convenient online submission

- Rigorous peer review

- Open access: articles freely available online

- High visibility within the field

- Retaining the copyright to your article

Submit your next manuscript at $\gg$ springeropen.com 